\title{
Study on the Teaching Method of CAD/CAM Course in Independent College
}

\author{
Wen-ju SHAN ${ }^{1, a,{ }^{*}}$ \\ ${ }^{1}$ Zhuhai College of Jilin University, Zhuhai, Guangdong Province, China \\ a36486846@qq.com
}

Keywords: CAD/CAM, Teaching method UGNX.

\begin{abstract}
This paper introduces the importance of CAD/CAM course of mechanical major in Independent College and the reform of teaching content and teaching method of $\mathrm{CAD} / \mathrm{CAM}$ course. Including the CAD/CAM course and theory teaching, practice teaching, practice teaching integration and task driven teaching method and micro-lectures, MOOC teaching methods are in practical teaching.
\end{abstract}

\section{About CAD/CAM}

With the development of computer technology and other related technology, CAD/CAM technology has been increasingly improved, it has become the basic technology in the informatization of manufacturing industry. The application of $\mathrm{CAD} / \mathrm{CAM}$ technology in various industries is becoming more and more widely, the application level is also rising, at the same time the demand for applied talents is increasing. Therefore, CAD/CAM has become a major course of Engineering Specialty in Colleges and universities. The school hopes that through the curriculum set up to enable students to master the new technology, training to meet the needs of the engineering field [1] .

CAD/CAM technology involves a wide range of content, from the course title, two aspects including computer-aided design and computer-aided manufacturing. Computer-aided design refers to the use of the computer to complete the work in the process of product design (such as drawing, part design, assembly design, engineering analysis), and to improve the quality of product design, shorten the product development cycle, reduce the cost of products. Computer aided manufacturing refers to the use of the computer to complete the process from production to products manufactured, including process design, tooling design, Computer Aided NC programming, production planning, manufacturing process control, quality inspection and analysis etc..

CAD/CAM technology has its own characteristics, and these characteristics determine the characteristics of the CAD/CAM course.

(1) Interdisciplinary. CAD/CAM technology is an integrated technology, It includes information technology, automation technology and modern management technology, and combining with the traditional product design and manufacturing technology, CAD/CAM technology has become a supporting enterprise material flow, energy flow and information flow of system engineering. In this system, multi-disciplinary, multi technology integration, integration and optimization, and gradually form a complete curriculum system.

(2) Dynamic Development. CAD/CAM technology is a kind of dynamic technology, which absorbs the latest technical achievements, and applies it to the design, manufacture, production management, marketing and other aspects of the product. Therefore, with the continuous emergence of new technology and new ideas, the 
content of CAD/CAM curriculum will be updated, enriched and developed, which determines the dynamic and development of the course [2].

(3) Strong Practicability. CAD/CAM technology is a practical technology. The development of CAD/CAM technology has a clear demand orientation; it is not for the pursuit of high and new technology for the purpose, but focus on practical results. $\mathrm{CAD} / \mathrm{CAM}$ technology attaches great importance to the combination of technology and management, attaches great importance to the rationalization of the organization and management system of the product formation process, resulting in a series of new production methods combined with technology and management. Therefore, CAD/CAM technology has a strong practical significance and engineering significance.

\section{About UGNX Software}

UGNX software is interactive CAD/CAM 3D software, it is powerful, and the UG CAD module can easily achieve a variety of complex entities and modeling. UG CAE module can realize the structural analysis, optimization design and kinematics simulation of complex engineering and product structure. UG CAM module can easily realize the parts manufacturing simulation. UGNX software is widely used in machinery, mold, automotive and aerospace fields. Zhuhai College of Jilin University has 100 sets of NX genuine software donated by the United States UGS company, and established the manufacturing information technology training base. The teaching of NX software has always been a feature of our college, Our College has the advantage of learning, applying and teaching the software. Based on the above reasons, our college CAD/CAM courses are using UGNX software [3].

\section{The Reform of CAD/CAM Course Teaching Content}

CAD/CAM application ability training is achieved through a series of courses. The course system should be run through the whole four years of undergraduate teaching system, rather than through the isolation of separate curriculum training. The application should run through engineering graphics, mechanical design, mechanical principle, CNC machining technology, machinery manufacturing technology, and the metalworking practice course. The following introduction is the combination of CAD/CAM course with Theoretical course, curriculum design, and practice course.

(1) CAD/CAM Course Combined with Theoretical Teaching. In the process of teaching engineering graphics, the projection of intersection and intersecting line is key and difficult point. The traditional teaching method is to demonstrate the physical model for the students, and then to explain the three-dimensional graphics or animation in Multimedia Courseware. Through the physical model can make students see cutting three-dimensional or intersecting three-dimensional shape and intersecting line shape features, there is some help for the projection of the three-dimensional surface intersection. Multimedia courseware through the display has been made in advance of three-dimensional graphics or animation, play a supplementary and complementary role. However, it is difficult to show the principle and process of the projection of intersecting lines, so it is difficult to understand. The 3D model created using UG NX software, not only can clearly and visually display the shape cutting three-dimensional, intersecting and even stereo combination, and the line of intersection shape feature, It can replace the physical teaching model and some animation functions of multimedia courseware. By virtue of its powerful rendering function, it can vividly show the 
surface characteristics of the actual shape, such as color, material, gloss, etc., to give people a more realistic sense of physical and three-dimensional [4] .

(2) CAD/CAM Course Combined with Curriculum Design. The curriculum design of mechanical principle is to train the students' ability to solve the practical problems by using the theoretical knowledge acquired in the course of mechanical principle. It is a practical teaching link for students to get engineering skills. Motion simulation is the main part of the UG CAE module, which can carry on the complex kinematics analysis, the dynamic analysis and the design simulation to the two-dimensional or three-dimensional mechanism. Through the UG /Modeling function to create a 3D model of movement scheme, using the UG /Motion function for each component gives certain kinematic characteristics, and then set up the connection between the various components in a certain can build a simulation model. The function of UG Motion can carry on a large number of assembly analysis, motion analysis and so on, such as interference inspection, track envelope .The motion parameters of the mechanism can be obtained. The kinematic and dynamic analysis of the kinematic simulation model can verify the rationality of the design, And can be used to output the various parts of the displacement, coordinates, acceleration, velocity and force changes, to optimize the motion mechanism [5] .

(3) CAD/CAM Course Combined with Metalworking Practice. Metalworking practice should be based on teaching practice, and pay attention to improve the ability of practice and the cultivation of students' comprehensive ability, so that students can have the initiative in practice, so that they can think independently in practice, so as to improve their ability to analyze and solve problems.

Operation of CNC machine is an important part of the metalworking practice. In the traditional teaching of NC. Teachers generally explain the basic knowledge and basic operation of CNC machine tools, Subsequently give the NC code to the students for the actual processing. This causes students only simply understand the basic operation of $\mathrm{CNC}$ machine tools and the programming and processing parameter settings are not intuitive understanding. Through the CAD/CAM software, the design of the product, the computer drawing, the numerical control programming, the processing manufacture and so on link up, causes the student to have the intuitive understanding to the product production entire process.

UGNX has the function of programming and simulation, after the completion of the program can be three-dimensional entity simulation processing. In the simulation process, the tool moves along the defined machining path. Students not only can intuitively grasp the process of NC machining, the tool path to determine the continuity, rationality, the existence of tool interference, collisions and so on, but also can deepen our understanding of the process of understanding and recognition of tool path. After the completion of the simulation by UGNX software, the program can be transferred to the $\mathrm{NC}$ machine for practical processing.

\section{Reform of CAD/CAM Teaching Method}

In the traditional teaching methods, teachers mainly explain the menu functions, software interface, parameter settings. The explanation of the software becomes mechanical and model, Knowledge is trivial, messy, and difficult to remember, The learning process is boring and the students' learning enthusiasm is gradually reduced. Teaching quality can not be guaranteed.

We should establish and perfect the teaching system of theory and practice, and actively explore the reform of teaching methods. To improve students' ability of 
combining theory with practice and to cultivate the spirit of innovation, fully mobilize the initiative and enthusiasm of students, combined with the characteristics of professional courses, emphasizing the effectiveness of the methods

MOOC is an acronym of Massive Open Online Course, The term came into existence in 2008, and was rapidly gaining popularity, expansion, and evolution.

The traditional teaching mode in colleges and universities is based on "teaching" MOOC will be digital, information and network of the new teaching model and based on " learning" Impact on traditional teaching mode.

Micro course refers to the video as the main carrier to record the whole process of teaching and learning activities based on the key and difficult points or teaching links. Based on the idea of instructional design, the use of multimedia technology are within five minutes of a knowledge point for targeted explanation. The micro course not only pays attention to teaching, but also pays attention to learning. The core content of micro course is classroom teaching video. Micro class is different from the traditional single resource type teaching resources, and is a kind of new teaching resources based on the inheritance and development of traditional teaching resources [6].

For the CAD/CAM course, we should use the modern teaching methods including PPT, video, animation, software demonstration and so on. So that the classroom teaching can give students more information. For example, some simple modeling, can be directly demonstrated to the students through the way of software presentation, and for some complex assembly simulation process, can be recorded in advance, through video playback. Through the full application of information technology, the teaching time is mainly used for the analysis of the key content, and intuitive display of various processes, is conducive to students' understanding of the curriculum content, thereby significantly improving teaching effectiveness.

\section{Acknowledgement}

This research was financially supported by Zhuhai Premier-Discipline Enhancement Scheme of Vehicle engineering (Zhuhai College of Jilin University). (Fund code: 2015YXXK14)

\section{References}

[1] N. Jin, L.Jiao, YB.Liu, The present situation and reform of CAD/CAM Technology Teaching, Journal of Liaoning Technical University. 5(2010)203.

[2] J. Ma, YQ.Xiao, CAD/CAM teaching and practice based on Modularization, Shanxi Science and Technology. 2(2010)140.

[3] L. Wang, EG.Zhang, Application of NX software in the teaching of manufacturing technology foundation, Examination weekly. 5(2009)187.

[4] N. Cui, The application of UG NX software in the engineering graphics Teaching, Educational Technology. 5(2011)167.

[5] CM. Zhang, N. Cui, Teaching reform and practice of mechanical principle course design in Independent Colleges, Scientific Information. 8(2013)15.

[6] DM. Li, A study on the foreign language teaching mode of MOOC, Overseas English. 8(2015)81. 